\title{
Primary Intradural Extramedullary Spinal Burkitt's Lymphoma: A Case Report
}

This article was published in the following Dove Press journal:

International Medical Case Reports Journal

\author{
Senai Goitom Sereke (ID) \\ Felix Bongomin (D) ${ }^{2,3}$ \\ Zeridah Muyinda ${ }^{4}$ \\ 'Department of Radiology and \\ Radiotherapy, School of Medicine, \\ Makerere University College of Health \\ Sciences, Kampala, Uganda; ${ }^{2}$ Department \\ of Medicine, School of Medicine, \\ Makerere University College of Health \\ Sciences, Kampala, Uganda; ${ }^{3}$ Department \\ of Medical Microbiology and Immunology, \\ Faculty of Medicine, Gulu University, \\ Gulu, Uganda; ${ }^{4}$ Department of Radiology, \\ Mulago National Referral Hospital, \\ Kampala, Uganda
}

Background: Non-Hodgkin's lymphoma (NHL) rarely involves the spine primarily, and if it does, is almost always associated with advanced disease.

Case Presentation: An 8-year-old male presented with a one month history of nuchal pain followed by stiffness and rapidly progressive upper and lower limb weakness. He was seronegative for HIV and EBV. Computed tomography myelogram and magnetic resonance imaging of the cervical and thoracic spine showed a long segment (C2 to T1) complete absence of cerebrospinal fluid signal and mildly enhancing intradural extramedullary lesion with an extradural and right paravertebral muscle extension, respectively. Post-excision biopsy histopathology and immunohistochemistry confirmed the diagnosis of a CD 10+, CD20+, CD45+, Bcl-2+, Ki67+, and EBER in situ hybridization for EBV negative, Burkitt's lymphoma (BL). Cytogenetic analysis showed chromosomal translocations of 8q24. CHOP plus intrathecal cytarabine, methotrexate was given as chemotherapy regimen. 1.8 grays (Gy) per fraction to the local area for an average total dose of 36 Gy was given with a resultant significant clinical improvement.

Conclusion: Though considered uncommon spinal canal tumors, BL should be in the differential diagnosis, if multilevel involvement is demonstrated on imaging.

Keywords: spinal, intradural, extramedullary, non-Hodgkin's lymphoma (Burkitt's)

\section{Background}

The spinal epidural space is an uncommon site in non-Hodgkin's lymphoma (NHL) and accounts for $9 \%$ of spinal epidural tumors and $0.1-6.5 \%$ of all lymphomas. ${ }^{1,2}$ Burkitt's lymphomas (BL) are small noncleaved B-cell lymphomas with highly aggressive clinical features. ${ }^{3} \mathrm{BL}$, in the epidural space, if it presents with neurologic deficits from compression of the spinal cord or spine nerve root, it is often associated with advanced disease. ${ }^{4}$ Spinal lymphomas can grow in a different pattern, in which hematogenous involvement is the most common. ${ }^{5}$ In this report, we present an unusual case of primary intradural extramedullary BL presenting acutely in a pre-pubertal Ugandan male.

\section{Case Presentation}

An 8-year-old male child presented with a three weeks history of neck pain associated with neck stiffness that was temporarily relieved by analgesic medication and massage, followed by a one-week history of weakness of all four upper and lower limbs impairing his ability to sit and stand. This was shortly followed by bladder and bowel incontinence. There was no history of cough, loss of weight, fever, or night sweats.
Correspondence: Senai Goitom Sereke Makerere University College of Health Sciences, P.O. Box 7072, Kampala, Uganda Tel +256-786-27l-349

Email nayhersen@gmail.com
International Medical Case Reports Journal 2020:13 70I-705 
The child was seronegative for Human immunodeficiency virus (HIV) and Epstein-Barr virus (EBV) infection. The boy was previously healthy before the onset of the neck pain. He is the second born of three siblings and the rest of the children are in good state of health.

On examination, he was lying supine in bed unable to sit or stand. There was no cervical or thoracic vertebrae gibbus or kyphus deformity. The dermatomes were intact in the upper and lower limbs. The myotomes at C5 were 3/5 of the right and $2 / 5$ of the left upper limbs. The perianal sensation was present. The myotomes at C6-T12 were 1/5 for both upper limbs and L2, L3, L4, L5, S1 were 1/5. The tone of upper and lower limbs was reduced. The muscle bulk and the reflexes were normal. Bulbocavernous reflex was positive. There were no enlarged cervical or inguinal lymph nodes. No clinical bladder or bowel disturbances were noted.

The complete blood count was normal (Hb-15.2g/dl, WBC-7300/mL, platelets $153,000 / \mu \mathrm{L})$. The erythrocyte sedimentation rate and liver function test were normal. The abdominopelvic ultrasound was unremarkable with no evidence of enlarged para-pancreatic, para-aortic, pelvic lymph nodes.

Anteroposterior and lateral view (flexion) plain radiography of cervical spine was unremarkable. MRI of the cervical and thoracic spine demonstrated an infiltrating intradural extramedullary, isointense on $\mathrm{T} 1$ and hyper intense on $\mathrm{T} 2$, mildly enhancing spinal cord lesion involving $\mathrm{C} 2-\mathrm{C} 4$ with an extension to extradural space of C3-T2. The lesion also extended to the right semispinalis cervicis, semispinalis capitis, trapezius, lavatory scapulae, and the anterior scalene muscles. Severe spinal stenosis was demonstrated in a long segment from C3-T2. There were no cervical or thoracic vertebral marrow changes (Figures 1 and 2). Computed tomography (CT) myelogram demonstrated a complete absence of contrast in the leptomeningeal space from $\mathrm{C} 2$ to
T1 while uniform opacification of the space below T1. MR myelogram confirmed the CT myelogram findings (Figure $3)$. There was no suspicious lesion in the bony cervical and thoracic vertebrae. There were no enlarged cervical lymph nodes noted. Hence, based on the imaging findings, the provisional diagnosis of intradural extramedullary spinal tumor with an extra spinal canal extension and a differential diagnosis of lymphoma was made.

The patient underwent laminectomy and decompression of the spinal stenosis. Jelly like extradural lesion extending below $\mathrm{C} 3$ to $\mathrm{T} 1$ was removed intraoperatively. The histopathology was consistent with a high-grade B cell lymphoma. The immunohistochemistry staining showed positivity for CD45, CD20, CD10, Bcl-2, and $>99 \%$ positivity of $\mathrm{Ki} 67$ (high proliferative index) (Figure 4). Epstein-Barr encoding region (EBER) in situ hybridization for EBV was negative. Cytogenetic analysis showed chromosomal translocations of $8 \mathrm{q} 24$.

The patient was put on radio-chemotherapy and clinically improved over 2 months period. The chemotherapy regimens were cyclophosphamide, doxorubicin hydrochloride, vincristine sulfate, and prednisone (CHOP) plus intrathecal cytarabine, methotrexate, and hydrocortisone for four cycles. The radiation dose was 1.8 grays (Gy) per fraction to the local area for an average total dose of 36 Gy, five days a week for four weeks. The upper and lower limb paresis improved significantly. Muscle power in upper limbs improved from $1 / 5$ to $5 / 5$ and those of the lower limbs improved from $1 / 5$ to $4 / 5$.

\section{Discussion}

Burkitt's lymphoma (BL), a highly aggressive and yet curable NHL was first described among Ugandan Children by Dr. Burkitt in late 1950s. ${ }^{6}$ Jaw and abdominal

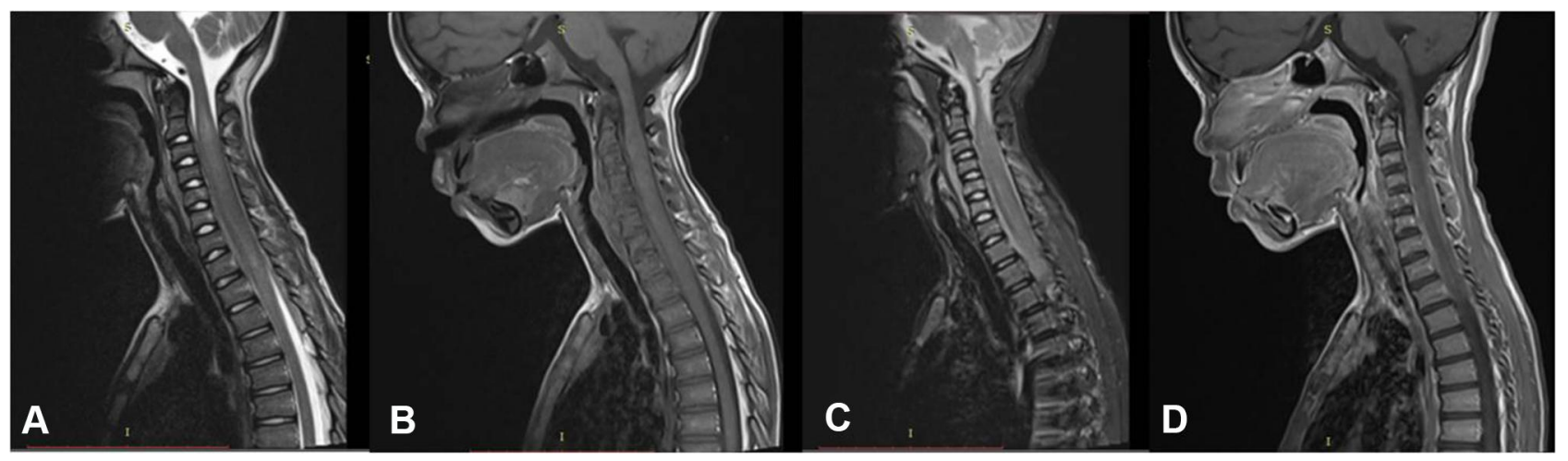

Figure I (A) T2 mid-sagittal (B) TI mid-sagittal (C) STIR mid-sagittal (D) TI+C mid-sagittal, demonstrated an infiltrating intradural extramedullary, isointense on TI and hyper intense on T2, mildly enhancing spinal cord lesion involving C2-C4 with an extension to extradural space of C3-T2. 


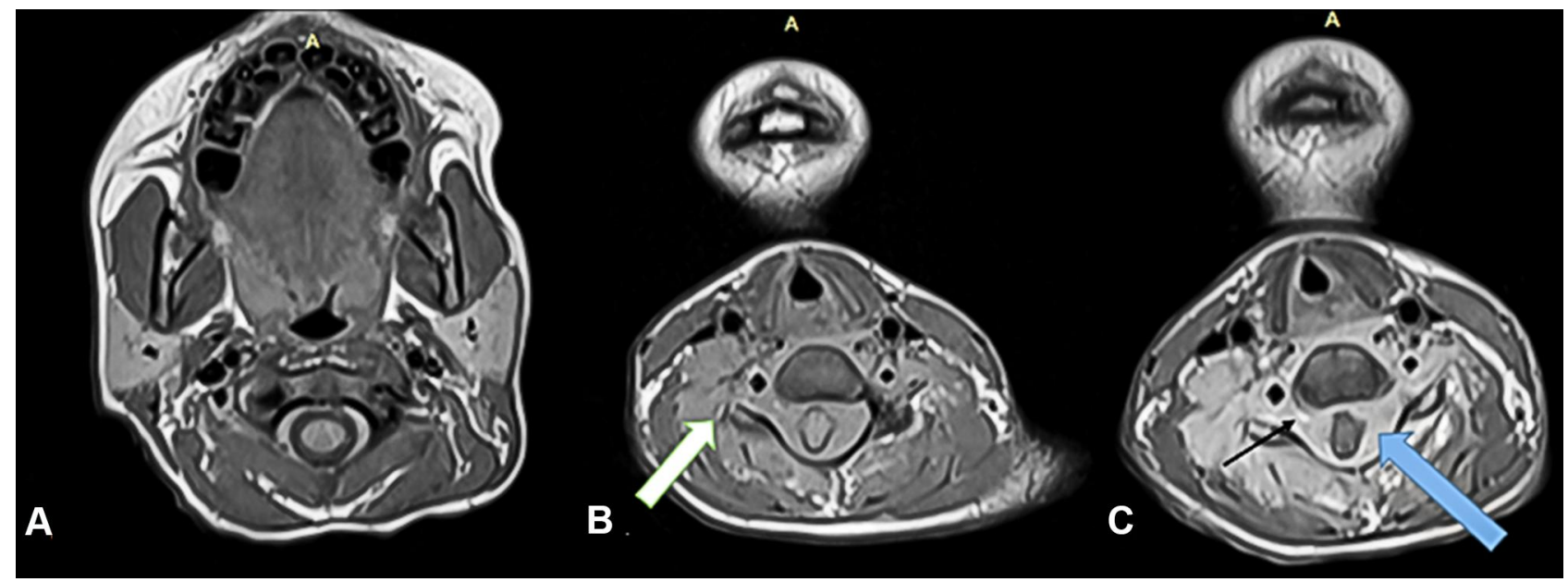

Figure 2 (A) $\mathrm{Tl}$ axial at $\mathrm{C2}(\mathbf{B}) \mathrm{TI}$ axial at $\mathrm{C} 4(\mathbf{C}) \mathrm{TI}+\mathrm{C}$ at $\mathrm{C}$, demonstrated circumferential enhancing lesion in the intradural and extramedullary space with severe spinal stenosis (blue arrow), the lesion exits the spinal canal via neural exit foramina (black arrow), extended to the right semispinalis cervicis, semispinalis capitis, trapezius, lavatory scapulae and the anterior scalene muscles (white arrow).

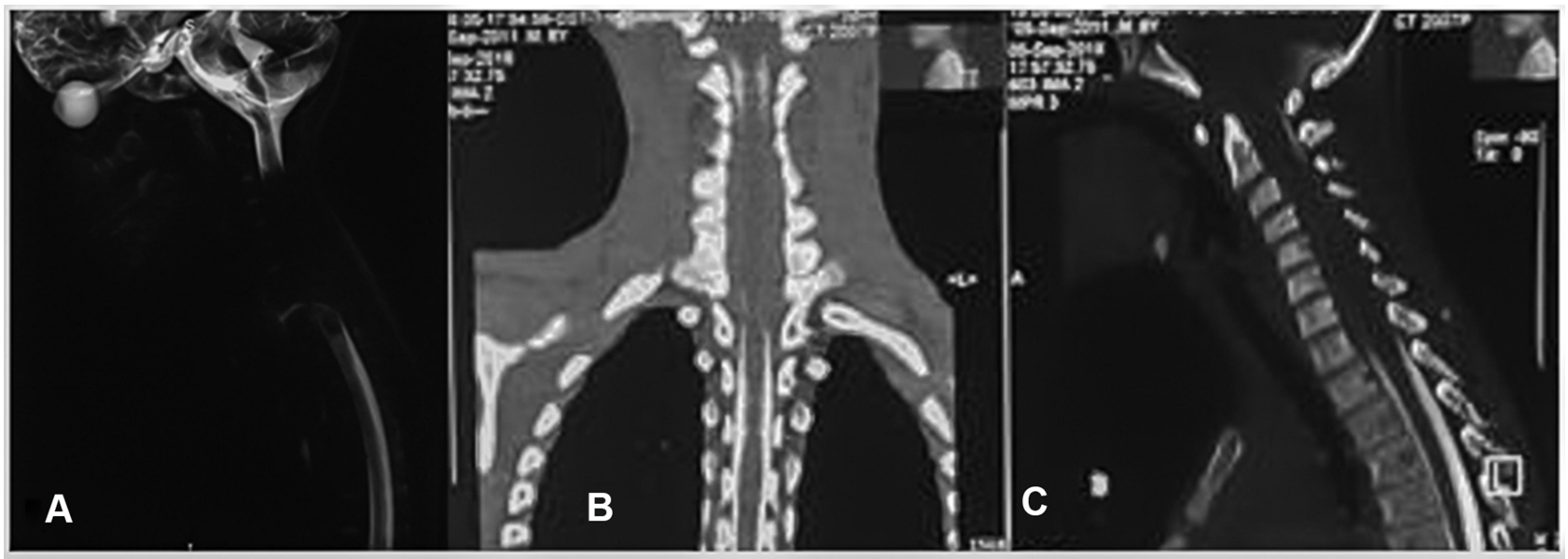

Figure 3 (A) MRI myelogram (B) CT myelogram coronal (C). CT myelogram mid-sagittal, demonstrated a complete absence of contrast (broken stick appearance of conventional myelography) in the leptomeningeal space from C2 to TI while uniform ossification of the space below TI.

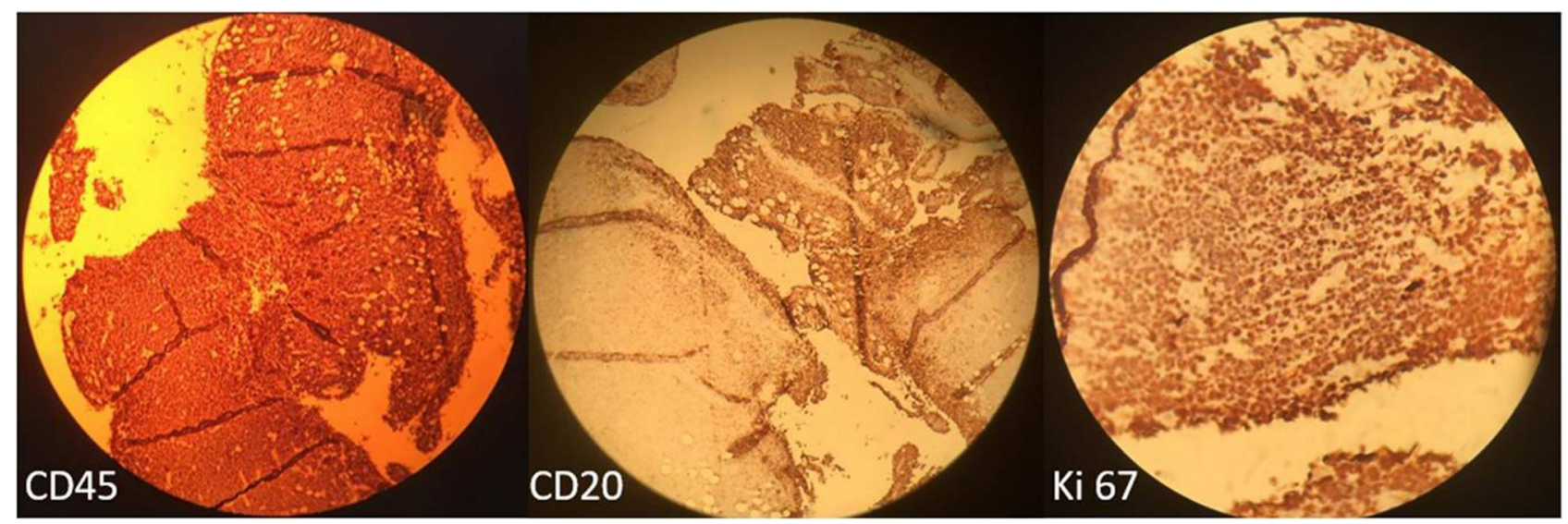

Figure 4 Immunohistochemistry demonstrated positivity of CD45, CD20 and Ki 67 which were features of high-grade B cell lymphoma. 
BL are the most common clinical presentations in Uganda. ${ }^{7}$ Primary spinal lymphoma is rare with under fifty cases reported in the literature. ${ }^{8}$ Most of these tumors occur extradurally with rare cases reported of spinal intradural BL. ${ }^{9}$ The present case demonstrates an extension of the intradural extramedullary lesion to an extradural space and surrounding musculature.

Clinical presentation of spinal lymphoma typically includes weakness, numbness, and progressive difficulty in ambulation. ${ }^{10}$ The thoracic spine is the most commonly affected site, followed by the cervical, less commonly the lumbar region, and most of them are solitary. ${ }^{11,12}$ The present case presented with neck pain and which was followed by limbs weakness and then subsequently quadriplegia.

Magnetic resonance imaging (MRI) with contrast is the preferred modality for the evaluation of spinal cord and spinal canal tumors. ${ }^{13}$ On MR, lymphoma appears as single or multifocal, ill-defined T2W/FLAIR hyperintense lesions with homogenous contrast enhancement on T1W images. ${ }^{14}$ Because of high cell tumor density, diffusionweighted MRI often demonstrates restriction and correspondingly hyperintensity. ${ }^{14,15}$ In the present case, the lesion was multilevel and hyperintense on $\mathrm{T} 2$ and mildly enhancing post gadolinium. Metastasis to intradural extramedullary space was a radiologic differential diagnosis; however, the absence of primary and supportive radiologic features of spinal canal lymphoma favored the latter. There was no upper motor neuron lesion clinically; hence, no brain imaging was done.

According to the 2008 World Health Organization (WHO), small B-cell lymphoma with plasmacytic differentiation is a diagnosis reserved for B-cell lymphomas with surface marker positivity for $\mathrm{CD} 19+, \mathrm{CD} 20+, \mathrm{CD} 38$ + , and CD $45+.{ }^{16}$ Histopathology of the tumor was suggestive of NHL. The immunohistochemistry showed strong positivity for CD20, CD45, and Ki 67, which confirmed the diagnosis.

All patients with primary spinal extramedullary lymphoma reported in the literature underwent surgery, which was similar to our patient's initial management to decompress the spinal stenosis. ${ }^{17,18}$ The patient was first treated by surgical decompression of the spinal cord stenosis.

Treatment of spinal cord lymphoma should include high-dose of intravenous methotrexate-based chemotherapy similar to regimens used with central nervous system lymphoma involving the brain. Spinal lymphoma responds very well to radiation treatment alone. ${ }^{18,19}$ The combined chemo-radiation, including intrathecal cytarabine and methotrexate, showed a better outcome and long-term survival. ${ }^{12}$ The patient was put on chemo-radiation, CHOP plus intrathecal cytarabine, methotrexate and radiation following decompression surgery and histopathologic diagnosis of the lesion. The patient showed significant clinical response.

\section{Conclusion}

Primary spinal intradural lymphoma is a rare entity in the spinal intradural extramedullary space and especially when there is an extradural extension. There are no pathognomonic imaging findings that allow flawless differentiation of lymphoma from other intradural spinal tumors, the combination of MR imaging findings and histopathology often permits one most likely diagnosis to be posited.

\section{Abbreviations}

BL, Burkitt's lymphoma; Bcl-2, B-cell lymphoma 2; CD, cluster of differentiation; $\mathrm{CT}$, computed tomography; CHOP, cyclophosphamide, doxorubicin hydrochloride, vincristine sulfate, and prednisone; EBER, Epstein-Barr encoding region; EBV, Epstein-Barr virus; FLAIR, fluid attenuation inversion recovery; Gy, Grays; HIV, human immunodeficiency virus; MRI, magnetic resonance imaging; NHL, non-Hodgkin's lymphoma; T1WI, T1 weighted imaging.

\section{Data Sharing Statement}

The information used and/or analyzed during this case report is available from the corresponding author on reasonable request.

\section{Ethics Approval and Consent to Participate}

No institutional approval was required to publish the case details. The parent's of the child provided an informed written consent to participate in the study of their child's condition.

\section{Consent for Publication}

The parents of the child provided an informed written consent for this case to be published in a peer-reviewed journal.

\section{Acknowledgments}

We would like to acknowledge the patient and patient's parent, the staffs of the radiology department of Mulago 
National referral hospital, spinal ward team and the medical oncology team for they actively supported the process of data collection and follows up updates of the patient.

\section{Author Contributions}

All authors made a significant contribution to the work reported, whether that is in the conception, study design, execution, acquisition of data, analysis and interpretation, or in all these areas; took part in drafting, revising or critically reviewing the article; gave final approval of the version to be published; have agreed on the journal to which the article has been submitted; and agree to be accountable for all aspects of the work.

\section{Funding}

No funding.

\section{Disclosure}

The authors declare that they have no competing interests.

\section{References}

1. Córdoba-Mosqueda ME, Guerra-Mora JR, Sánchez-Silva MC, Vicuña-González RM, Ibbara-de la Torre A. Primary spinal epidural lymphoma as a cause of spontaneous spinal anterior syndrome: a case report and literature review. J Neurol Surg Rep. 2017;78(1):e1-4.

2. Freeman C, Berg JW, Cutler SJ. Occurrence and prognosis of extranodal lymphomas. Cancer. 1972;29(1):252-260.

3. Thomas DA, O'Brien S, Faderl S, et al. Burkitt lymphoma and atypical Burkitt or Burkitt-like lymphoma: should these be treated as different diseases? Curr Hematol Malig Rep. 2011;6(1):58-66.

4. Kim Y-S, Lee J-K, Choi K-Y, Jang J-W. Spinal Burkitt's lymphoma mimicking dumbbell shape neurogenic tumor: a case report and review of the literature. Korean J Spine. 2015;12(3):221-224.

5. Li MH, Holtås S, Larsson EM. MR imaging of spinal lymphoma. Acta Radiol. 1992;33(4):338-342.
6. Walusansa V, Okuku FM, Orem J. Burkitt lymphoma in UGANDA, the legacy of Denis Burkitt and an update on the disease status. $\mathrm{Br}$ J Haematol. 2012;156:757-760.

7. Orem J, Mulumba Y, Algeri S, et al. Clinical characteristics, treatment and outcome of childhood Burkitt's lymphoma at the Uganda Cancer Institute. Trans R Soc Trop Med Hyg. 2011;105:717-726.

8. Yang W, Garzon-Muvdi T, Braileanu M, et al. Primary intramedullary spinal cord lymphoma: a population-based study. Neuro-Oncol. 2017;19(3):414-421.

9. Cugati G, Singh M, Pande A, et al. Primary spinal epidural lymphomas. J Craniovertebral Junction Spine. 2011;2(1):3-11.

10. Çeçen DA, Tatarlı N, Turan Süslü H, Özdoğan S, Barışık NÖ. Primary dural spinal lymphoma presentation of a rare spinal tumor case. Case Rep Surg. 2015;2015:639253.

11. Moussaly E, Nazha B, Zaarour M, Atallah JP. Primary NonHodgkin's lymphoma of the spine: a case report and literature review. World J Oncol. 2015;6(5):459-463.

12. Cugati G, Singh M, Symss NP, Pande A, Vasudevan MC, Ramamurthi R. Primary spinal intradural extramedullary lymphoma causing cauda equina syndrome. J Craniovertebral Junction Spine. 2012;3(2):58-61.

13. Shekdar KV, Schwartz ES. Imaging pediatric spine tumors. Appl Radiol. 2014;43(11):26-40.

14. Koeller KK, Rosenblum RS, Morrison AL. Neoplasms of the spinal cord and filum terminale: radiologic-pathologic correlation. Radiographics. 2000;20(6):1721-1749.

15. Abrey LE, Yahalom J, DeAngelis LM. Treatment for primary CNS lymphoma: the next step. J Clin Oncol. 2000;18(17):3144-3150.

16. Campo E, Swerdlow SH, Harris NL, Pileri S, Stein H, Jaffe ES. The 2008 WHO classification of lymphoid neoplasms and beyond: evolving concepts and practical applications. Blood. 2011;117 (19):5019-5032.

17. Kim SK, Lee SH, Kim ES, Eoh W. Diffuse large B-cell lymphoma mimicking schwannoma of lumbar spine. Korean J Spine. 2016;13 (2):71-73.

18. Do AS, Smith GA, Pace J, Hdeib A, Kasliwal MK. Primary spinal intradural extramedullary lymphoma: a novel management strategy. J Clin Neurosci. 2017;35:122-126.

19. Hashemi-Sadraei N, Peereboom DM. Chemotherapy in newly diagnosed primary central nervous system lymphoma. Ther Adv Med Oncol. 2010;2(4):273-292.

\section{Publish your work in this journal}

The International Medical Case Reports Journal is an international, peer-reviewed open-access journal publishing original case reports from all medical specialties. Previously unpublished medical posters are also accepted relating to any area of clinical or preclinical science. Submissions should not normally exceed 2,000 words or 4 published pages including figures, diagrams and references. The manuscript management system is completely online and includes a very quick and fair peer-review system, which is all easy to use. Visit http://www.dovepress.com/testimonials.php to read real quotes from published authors. 